\title{
The Challenges Facing Arab Researchers in Using English References in Research
}

\author{
Bushra Wahid Ali ${ }^{1}$, Shebli Younus Idham ${ }^{2} \square$ and Rabaa Said Mohamed Aljngawi ${ }^{3}$ \\ ${ }^{123}$ Department of English language, School of languages, literacies and translation, Universiti Sains Malaysia, Malaysia \\ $\square$ Corresponding Author: Shebli Younus Idham, E-mail: shebliyounus@gmail.com
}

\begin{tabular}{|c|c|}
\hline ARTICLE INFORMATION & ABSTRACT \\
\hline $\begin{array}{l}\text { Received: } 08 \text { October } 2021 \\
\text { Accepted: } 14 \text { November } 2021 \\
\text { Published: } 22 \text { November } 2021 \\
\text { Dol: } 10.32996 / \text { jeltal.2021.3.12.3 }\end{array}$ & $\begin{array}{l}\text { This study investigates why Arabic researchers do not employ English references and } \\
\text { citations in their studies. Even though many colleges and universities teach English in } \\
\text { their undergraduate and postgraduate stages, Arabic researchers face real challenges } \\
\text { in using English language references. This is due to apparent weakness in their English } \\
\text { language competency, and teaching, learning, and assessing at schools, colleges, and }\end{array}$ \\
\hline $\begin{array}{l}\text { References, English, Arabic, } \\
\text { International, Research }\end{array}$ & $\begin{array}{l}\text { universities. As a result, graduates with poor English language skills from colleges and } \\
\text { universities with various scientific credentials and specialties, particularly the } \\
\text { humanistic specialization, are produced. This, in turn, has a significant impact on the } \\
\text { quality of the research and studies they perform both before and after graduation. This } \\
\text { weakness is also due to their independence and general ignorance of the English } \\
\text { language, so they rely primarily on Arabic references, rarely using English language } \\
\text { references. As a result, they miss out on a significant amount of information, valuable } \\
\text { studies, significant research, and a vast amount of scientific areas. The study data } \\
\text { consisted of } 76 \text { Arabic journals to determine to what extent Arabic researchers employ } \\
\text { English references in their studies compared to Arabic ones. The findings revealed that } \\
\text { the researchers depend on Arabic references when they do their research. Indeed, this } \\
\text { will impact the overall quality of Arabic research and development, resulting in a frail } \\
\text { motivation towering over the world's correspondences. Some recommendations were } \\
\text { made to develop remedies and enhance researchers in the Arab world. }\end{array}$ \\
\hline
\end{tabular}

\section{Introduction}

Referencing is a system used by academicians to indicate the source of the ideas, theories, quotes, facts, or any other evidence, data, and information that has been used for any write-up or assignment. References use can be a good illustration for the researcher's English language adequacy. It is an essential part of any scientific writing and one must do this in all the academic assignments (Sharma, 2019).

Arab researchers mainly depend on Arabic references and sources such as articles, books, and journals. The lack is mainly because of their weak English language competence; the Arabic teaching system as a second language is the main factor. This research will shed light on a random sample of Arabic humanistic researchers from different countries and colleges of different universities. The researchers chose the humanistic specialization because it uses Arabic in teaching, learning, curriculum, and researching. Therefore, we pick up the bibliographies of this specializations' research to find out to what extent the English language references have been used in these researches compared to the Arabic references. The random sample of different Arabic country universities shows a considerable gap between Arabic and English references used on the Arabic humanistic researchers.

The English language is essential at the research level because it is the international scientific language worldwide. Moreover, excluding the English language references in any work excludes a considerable part of international information. Natalia Fernández Díaz-Cabal (2016) stated that "publishing academic writings in English was a necessary luxury to have an internationally oriented curriculum vitae (CV)," and she added that" Nowadays, it is more than that: it is a mandatory step for the "market" of indexed journals. (Ibid)

Copyright: (C) 2021 the Author(s). This article is an open access article distributed under the terms and conditions of the Creative Commons Attribution (CC-BY) 4.0 license (https://creativecommons.org/licenses/by/4.0/). Published by Al-Kindi Centre for Research and Development, London, United Kingdom. 
Tardy (2014), in his paper, stated that "English may be seen as a neutral lingua franca, or it may be seen more insidiously as a dominating and overpowering force. Moreover, English is a universal language in the world used in scholarly works and publications (Crystal, 2003).

Al-Mahrooqi (2015) emphasized that Omani students continued to graduate from high schools with insufficient English language ability, with the majority enrolling in intensive English language courses. This study examined data from a questionnaire distributed to 100 (tertiary) students; she proposed some remedies and urged students to learn English by raising their international awareness of the language's status and relevance. The findings unequivocally demonstrated that teachers were underprepared and underqualified. They employed archaic, tedious traditional teaching methods, their proficiency was limited, and their competence was lacking. Additionally, teachers spoke plainly in the classroom.

Moreover, Al-Mahrooqi portrayed academic writing as deceptively complex, formal, and objective. She found that English was widely used for academic research on a global scale. It was the language of many academic publications, and that fundamental characteristics of the English language, such as vocabulary and punctuation, were beneficial for academic writing.

In his paper, Tardy (2014) studied the roles of the English International Language as a Scientific aspect through different viewpoints of international graduated students. This was by outlining a questionnaire and a group interview study to determine the students' English attitudes and role in scientific communication. The researcher found out the study, which was discussed in light of published conversations of students and their implications for English as a tool for scientific communication.

\section{Methodology}

Research references and their management as a study output are dependent on more than the researcher's methodology, conclusions, and expertise. Additionally, it depends on other researchers' ideas and primary and secondary sources of information such as books, journals, abstracts, theses, reports, monographs, e-publications, and web sources. These additional sources back the researcher's objectives and arguments. These quotations, concepts, objectives, procedures, theories, interpretations, and other sources of knowledge are referred to as references used and supported in the current study effort. These sources must be cited to ensure the integrity of the communication and to avoid plagiarism (Murali Prasad, 2017).

References use and management is research output relays mainly on another researcher's global methodologies, results, and knowledge. Moreover, it depends mainly on the researcher's thoughts and sources such as the books, the articles, the abstracts, theses, reports, papers, e-publications, and web input. These outside references enrich and support the actual researcher's purpose of study and arguments. In short, all the types like words, quotations, ideas, aims, procedures, models, and interpretations and any information sources used or supported for the research are called 'references.' Also, these must produce a pure communication that avoids plagiarism. (Murali, 2017)

The researchers selected a random sample of 76 Arabic journals from humanistic colleges and universities in different Arab countries. The researchers tried their best to find humanistic data because they mostly use Arabic language curriculums during college and higher studies. Therefore, they tend to use English references; this is in comparison with humanistic qualifications. Also, scientific colleges use the English language in their study systems, strengthening the quality of their English language skills quality. The use of Arabic and English references of humanistic specialization can be seen in appendix 1.

\section{Findings}

The authors of the humanistic study use 2014 Arabic references compared to 1264 English references. The findings provide undeniable evidence that Arabic humanistic scholars avoid using English references, and this scarcity of foreign works and information generates a material shortage. Furthermore, researchers confront the problem of publication constraints because key publishers tend to write in English. This problem may be the most critical because the researcher faces the difficulty of knowledge communication. This difficulty has numerous consequences. The Arabic research will be limited. The limitation resides in the fact that their field of study will be limited, and they will be unable to cover a substantial amount of data. Researchers' lack of knowledge and information prohibits them from covering the most relevant facts and conclusions linked to their topic. His thoughts and knowledge are hampered from reaching a global audience.

The researcher's unawareness of the English language prevents him/her from the newest and latest global information spread around the world. This global info spread, and the researcher becomes unaware of the latest versions on his/her field. Moreover, the lack of knowledge delays the researcher's knowledge, the field of study, rank, college, university, country, and the whole Arabic world.

Why is this problem significant? The lack of English language used by the Arabic researchers prevents them from a large amount of information because there were about $25 \%$ of the world's inhabitants speaking the English language, and the rest are from different languages in which they, in turn, use the English language to publish their own investigates and studies. This leads to a 
kind of lack of scientific communication. Moreover, because the researcher needs to communicate with the other researchers to gain knowledge and exchange ideas worldwide, his English weakness made him sized with minimal information. Therefore, he is prevented from a vast majority of works, knowledge, ideas, global updates. Finally, this inquiry sheds light upon problematic references usage, especially the problem of English references rarely used by humanistic specialization workers at a random sample of Arabic universities' research papers. This is to find out the why?

Moreover, how to solve it, we found out that it is merely because of the English language unawareness of the most humanistic Arabic researchers. When the researcher faces the problem of weak English language competence so essentially, he tends to use the Arabic references more than the English language references; even if he uses the English references, he needs a translator that in turn is a new problem. The researcher's lack of rare effects ranks scholarly, and he cannot publish his research in high-ranked journals. Moreover, his college, university, and rank of his country and the Arabic world are consequently affected. Consequently, the whole Arabic world rank will be affected negatively because of a series and chained belongings. However, the solution and how to find out the keys to solving this problem is by giving more attention to the basics of English language teaching and learning, leading to improved researchers in the Arabic world.

\section{Conclusion}

The current study examined to what extent humanistic specialization researchers use English references in their studies. The findings of the study revealed that most humanistic scholars use Arabic references more than English references. This is due to a lack of resources and a lack of proficiency in the English language. Some of them, however, prefer to conduct studies on the English language. This is because they understand how to write and research in English quite effectively. This is because they study overseas. As a result, we know that English competency is absent primarily because English facts are not respected in Arabic society.

Based on the results of the study, some recommendations were made. First, researchers in the Arab world should improve their English language competence. Second, colleges and universities in the Arab world should improve the English research skills of students and instructors. Third, colleges and universities in the Arab world should shed more light on English language use, study, teaching, research, and people in general. Finally, higher education ministries of the Arab world should shed light on the English language level taught at schools, colleges, and universities.

\section{References}

[1] Al-Mahrooqi, R. I. (2015). Foreign language communication anxiety (FLCA) among tertiary level Omani EFL learners. Asian EFL Journal, 57-89.

[2] Chand, Z. A. (2014,). Language Learning Strategy Use and its Impact on Proficiency in Academic Writing of Tertiary Students. Procedia Social and Behavioral Sciences, 118:511-521.

[3] Prasad, M. R. (2017). Usage of References and Its Management in Research. In A. Munigal, Scholarly Communication and the Publish or Perish Pressures of Academia (118-142). The United States of America: IGI Global.

[4] Rao, V. C. (2020). Academic Language Proficiency: English for Academic Purposes (EAP)

[5] Sharma, N. (2019). Writing Reference. The role of English in scientific communication: Lingua franca or Tyrannosaurus Rex?

\section{Appendix}

\section{Appendix 1. Use of Arabic and English References of Humanistic Specialization Writers}




\begin{tabular}{|c|c|c|}
\hline No. & Arabic references used & English references used \\
\hline 1. & 36 & 0 \\
\hline 2. & 24 & 9 \\
\hline 3. & 42 & 0 \\
\hline 4. & 14 & 0 \\
\hline 5. & 60 & 6 \\
\hline 6. & 16 & 0 \\
\hline 7. & 27 & 13 \\
\hline 8. & 21 & 15 \\
\hline 9. & 15 & 0 \\
\hline 10. & 14 & 9 \\
\hline 11. & 19 & 0 \\
\hline 12. & 6 & 2 \\
\hline 13. & 6 & 12 \\
\hline 14. & 28 & 1 \\
\hline 15. & 38 & 1 \\
\hline 16. & 6 & 14 \\
\hline 17. & 3 & 16 \\
\hline 18. & 24 & 4 \\
\hline 19. & 20 & 8 \\
\hline 20. & 5 & 57 \\
\hline 21. & 25 & 6 \\
\hline 22. & 22 & 9 \\
\hline 23. & 33 & 13 \\
\hline 24. & 28 & 42 \\
\hline 25. & 5 & 18 \\
\hline 26. & 27 & 0 \\
\hline 27. & 31 & 0 \\
\hline 28. & 31 & 0 \\
\hline 29. & 47 & 0 \\
\hline 30. & 10 & 22 \\
\hline 31. & 0 & 0 \\
\hline 32. & 35 & 0 \\
\hline
\end{tabular}




\begin{tabular}{|c|c|c|}
\hline 33. & 22 & 5 \\
\hline 34. & 21 & 3 \\
\hline 35. & 63 & 17 \\
\hline 36. & 20 & 0 \\
\hline 37. & 59 & 0 \\
\hline 38. & 57 & 0 \\
\hline 39. & 23 & 0 \\
\hline 40. & 13 & 3 \\
\hline 41. & 23 & 5 \\
\hline 42. & 24 & 0 \\
\hline 43. & 16 & 10 \\
\hline 44. & 33 & 4 \\
\hline 45. & 7 & 16 \\
\hline 46. & 19 & 2 \\
\hline 47. & 22 & 0 \\
\hline 48. & 13 & 0 \\
\hline 49. & 2 & 15 \\
\hline 50. & 2 & 9 \\
\hline 51. & 0 & 58 \\
\hline 52. & 11 & 10 \\
\hline 53. & 9 & 0 \\
\hline 54. & 35 & 3 \\
\hline 55. & 0 & 90 \\
\hline 56. & 6 & 0 \\
\hline 57. & 12 & 0 \\
\hline 58. & 16 & 0 \\
\hline 59. & 5 & 12 \\
\hline 60. & 31 & 0 \\
\hline 61. & 16 & 4 \\
\hline 62. & 16 & 8 \\
\hline 63. & 18 & 0 \\
\hline 64. & 11 & 0 \\
\hline 65. & 2 & 0 \\
\hline
\end{tabular}


The Challenges Facing Arab Researchers in Using English References in Research

\begin{tabular}{l|l|l}
\hline 66. & 30 & 0 \\
\hline 67. & 15 & 0 \\
\hline 68. & 0 & 29 \\
\hline 69. & 51 & 0 \\
\hline 70. & 15 & 0 \\
\hline 71. & 32 & 1 \\
\hline 72. & 56 & 0 \\
\hline 73. & 55 & 0 \\
\hline 74. & 67 & 0 \\
\hline 75. & 8 & 19 \\
\hline 76. & 8 & 9 \\
\hline
\end{tabular}

